\title{
Cell Type-Specific MxA-Mediated Inhibition of Measles Virus Transcription in Human Brain Cells

\author{
SIBYLLE SCHNEIDER-SCHAULIES, ${ }^{*}$ J. SCHNEIDER-SCHAULIES, ${ }^{1}$ A. SCHUSTER, \\ M. BAYER, ${ }^{1}$ J. PAVLOVIC, ${ }^{2}$ AND V. TER MEULEN ${ }^{1}$ \\ Institute for Virology and Immunobiology, D-97078 Würzburg, Germany, ${ }^{1}$ and \\ Institute for Virology, University of Zürich, CH-8028 Zürich, Switzerland ${ }^{2}$
}

Received 16 March 1994/Accepted 25 July 1994

\begin{abstract}
Measles virus (MV)-specific transcription in human brain cells is characterized by particularly low abundances of the distal mRNAs encoding the MV envelope proteins. Similar transcriptional restrictions of the closely related vesicular stomatitis virus have been observed in mouse fibroblasts constitutively expressing the interferon-inducible MxA protein (P. Staeheli and J. Pavlovic, J. Virol. 65:4498-4501, 1991). We found that MV infection of human brain cells is accompanied by rapid induction and high-level expression of endogenous $\mathrm{MxA}$ proteins. After stable transfection of $\mathbf{M x A}$, human glioblastoma cells (U-87-MxA) released 50- to 100-fold less infectious virus and expression of viral proteins was highly restricted. The overall MV-specific transcription levels were reduced by up to $90 \%$, accompanied by low relative frequencies of the distal MV-specific mRNAs. These restrictions were linked to an inhibition of viral RNA synthesis and not to a decreased stability of the viral RNAs. Our results indicate that expression of $\mathrm{MxA}$ is associated with transcriptional attenuation of $\mathrm{MV}$ in brain cells, thus probably contributing to the establishment of persistent MV central nervous system infections. In addition, the mechanism of MxA-dependent resistance against MV infection, in contrast to that of vesicular stomatitis virus, is cell type specific, because an inhibition of MV glycoprotein synthesis independent of transcriptional alterations was observed in MxA-transfected human monocytes (J.-J. Schnorr, S. Schneider-Schaulies, A. Simon-Jödicke, J. Pavlovic, M. A. Horisberger, and V. ter Meulen, J. Virol. 67: 4760-4768, 1993).
\end{abstract}

Measles virus (MV) gene expression in persistent infections of the human central nervous system is characterized by the accumulation of viral ribonucleoprotein particles in neurons and glial cells and a strongly attenuated expression of the viral envelope proteins $(3,34)$. A hallmark of altered MV gene functions is the significant underrepresentation of the distal MV envelope gene-specific transcripts, which has been directly linked to the low expression of the corresponding proteins $(5$, 6). On the basis of experiments with neural tissue culture cells, MV transcription has been suggested to be controlled by components intrinsic to the host cell or induced by differentiation-dependent alterations of the intracellular cell metabolism $(30-33,42)$.

On the other hand, MV infection of brain cells in vivo and in vitro is accompanied by the release of cytokines $(13,14,29)$ that also may influence viral replication. This is based on the observation of type I interferon (IFN) in cerebrospinal fluid specimens of patients with persistent central nervous system infections such as subacute sclerosing panencephalitis (SSPE) $(13,14,19)$ and in MV infections of brain cells in tissue culture $(16,26,29)$. In addition, IFN-escape variants have been linked to enhanced neurovirulence in an animal model (4).

Among the variety of intracellular IFN-inducible proteins, the type I IFN-inducible Mx proteins have been characterized in the most detail and have been analyzed for their antiviral potential $(36,38)$. The nuclear mouse $\mathrm{Mx} 1$ protein was identified as an IFN-induced factor necessary and sufficient to confer a high degree of resistance exclusively to influenza $\mathrm{A}$ viruses to mammalian cells in tissue culture $(17,38,43,44)$.

* Corresponding author. Mailing address: Institute for Virology and Immunobiology, Versbacher Str. 7, D-97078 Würzburg, Germany. Phone: 931-201-5954. Fax: 931-201-3934.
Although the precise mechanisms interfering with primary transcription of influenza virus in Mx1-expressing cells have not been elucidated completely (17), the interference may be overcome by overexpression of the PB2 protein, which, together with its strict confinement to the nucleus, strongly suggests a direct interference with viral polymerase functions $(12,39)$. In contrast, the antiviral effects observed for the human cytoplasmic MxA protein are virus specific in restricting primary RNA synthesis of vesicular stomatitis virus (VSV) or inhibiting a step later than primary transcription for influenza virus in mouse $3 \mathrm{~T} 3$ cells constitutively expressing $\mathrm{MxA}(23,24$, 37). The MxA-dependent transcriptional inhibition of VSV was recently confirmed in stably MxA-transfected human monocytes. In the same study, a specific inhibition of viral glycoprotein synthesis independent of transcriptional restrictions was observed for MV in U-937 cells (35). It is suggestive that the multiple effects depend on host cell factors modifying the mode of action of MxA proteins $(10,27)$.

Because high levels of $\mathrm{Mx}$ proteins have been found in MV-infected neural cells $(16,29)$, we investigated the potential role of this protein in attenuating MV gene functions in brain cells. After stable transfection of a human glioma cell line (U-87-MxA), production of infectious MV was reduced by up to 2 logs compared with that of MxA-nonexpressing controls, similar to the effect described before for U-937-MxA cells (35). However, in U-87-MxA cells, synthesis of MV-specific transcripts was strongly attenuated, which was very similar to the restrictions described for VSV (37). Thus, these findings provide evidence that the antiviral activity of MxA protein may not only be virus and compartment specific but may also be host cell specific. In addition, the potential to attenuate MV gene functions in brain cells, together with the high level of expression after primary MV infection of brain cell cultures, 
renders the MxA protein a prime candidate for contributing to the establishment of persistent infections of the human central nervous system.

\section{MATERIALS AND METHODS}

Cell lines, viruses, IFN, and antibodies. Human glioblastoma D-54, U-251, U-138, D-32 (all kindly provided by $D$. Bigner $[2,40]), A-172$, and U-87; neuroglioma $H-4$; neuroblastoma SK-N-MC, SK-N-BE, and IMR-32; and HEL (human embryonic lung fibroblasts [all purchased from the American Type Culture Collection]) cells were grown in minimal essential medium containing $10 \%$ inactivated fetal calf serum. Vero cells (African green monkey kidney) were grown in minimal essential medium-5\% fetal calf serum in the presence of penicillin-streptomycin. Stocks of the MV Edmonston strain and the New Jersey serotype of VSV were grown and passaged on Vero cells with titers of $5 \times 10^{6}$ to $1 \times 10^{7} \mathrm{PFU} / \mathrm{ml}(\mathrm{MV})$ and $1.5 \times 10^{9} \mathrm{PFU} / \mathrm{ml}$ (VSV). Recombinant IFN- $\beta$ was obtained from Merck and used at a concentration of 1,000 $\mathrm{U} / \mathrm{ml}$ for $24 \mathrm{~h}$. Anti-IFN antibodies were used at final concentrations of 1,000 IFN neutralizing units (Boehringer, Mannheim, Germany). The monoclonal MxA antibody was raised against pHisMxA protein purified from Escherichia coli (25).

Establishment of stably transfected cell lines. U-87 cells lipofected with the expression plasmid APR-1-MxA (containing the entire coding sequence of the human MxA cDNA [1] under the control of the human $\beta$-actin promoter [35]) or with vector DNA (8) lacking the MxA fragment were selected for their resistance to $\mathrm{G} 418(500 \mu \mathrm{g} / \mathrm{ml})$. Transfectants were cloned twice by limiting dilution and analyzed for their MxA expression by immunofluorescent staining and subsequent fluorescence-activated cell sorter (FACScan) and Western immunoblot as described previously (35). Stable cell clones were subsequently maintained in the presence of $500 \mu \mathrm{g}$ of G418 per ml (Gibco BRL). Infection experiments with the transfectants were performed in standard medium lacking G418.

RNA extraction and Northern (RNA) blot analysis. RNA extraction and Northern blot analyses were performed as described previously (30). pGemMV-N and pGemMV-H $(5,6)$ were used as linearized templates for in vitro transcription of $\left[{ }^{32} \mathrm{P}\right] \mathrm{CTP}$-labeled antisense probes. The rat pGAPDH (7) and pHG327/MxA (1) were labeled with $\left[{ }^{32} \mathrm{P}\right] \mathrm{dCTP}$ by random priming by following the instructions of the manufacturer (Boehringer).

In vivo labeling of viral RNAs. Confluent monolayers were infected with MV Edmonston strain (multiplicity of infection [MOI] of 1) for $18 \mathrm{~h}$, starved for $1 \mathrm{~h}$ in phosphate-free medium (ICN Biochemicals) containing $50 \mu \mathrm{g}$ of actinomycin $\mathrm{D}$ per $\mathrm{ml}$, and subsequently labeled with $500 \mu \mathrm{Ci}$ of ${ }^{32} \mathrm{P}_{\mathrm{i}}$ per $\mathrm{ml}$ in the presence of $20 \mu \mathrm{g}$ of actinomycin $\mathrm{D}$ per $\mathrm{ml}$ for the time intervals indicated. Under these conditions, no detectable incorporation of label into cellular transcripts was apparent in uninfected cells $(9,20,22,41)$. After labeling, cells were extensively washed and chased in complete medium for the time intervals indicated or immediately harvested. Primary RNA synthesis was analyzed by direct labeling (described above) for $6 \mathrm{~h}$ after MV infection with an MOI of 10 in the presence of $20 \mu \mathrm{g}$ of cycloheximide per $\mathrm{ml}$ and $20 \mu \mathrm{g}$ of actinomycin D per $\mathrm{ml}$. Under these conditions, no incorporation of $\left.{ }^{35} S\right]$ methionine was detected in trichloroacetic acidprecipitable total cellular proteins (not shown). Total RNAs were prepared, separated on formaldehyde-containing agarose gels, and blotted onto a nitrocellulose filter. Quantification of the signals obtained was performed by scanning laser densitometry with a Molecular Dynamics PhosphorImager.

\section{RESULTS}

Expression and induction of MxA in cells of neural origin. In brain material isolated from patients with SSPE, expression of MxA-specific mRNA was associated with the presence of MV N-specific mRNA transcripts (Fig. 1a, lanes 2, 4, 6, 8, and 9 ), whereas MV-negative brain RNA samples from these patients (Fig. 1a, lanes 3, 5, and 7) were essentially negative for MxA mRNA. As revealed by immunofluorescence staining of SSPE brain sections, uninfected cells in the vicinity of infected ones expressed MxA, suggesting the induction of this protein by a soluble factor, most likely IFN (not shown).

In MV-infected tissue cultures, the expression of the MV $\mathrm{N}$-specific protein was preceeded by high levels of $\mathrm{MxA}$ proteins in some neural cell lines, as shown for the glioma cell line D-54 (Fig. 1b and Table 1), but not in HEL cells (Fig. 1c) used as nonneural control cells. However, in both cell lines, comparable levels of $\mathrm{MxA}$ could be induced upon exogenous treatment with recombinant IFN- $\beta$ (Fig. $1 b$ and $c$, lanes 6 and 5 , respectively). Titration experiments revealed that induction of MxA in D-54 and U-251 cells required up to 50-fold less IFN- $\beta$ than was required for HEL cells (not shown). Induction of MxA by MV infection could be reduced by about $60 \%$ in the presence of anti-IFN- $\beta$ antibodies, but not with anti-IFN- $\alpha$ and anti-IFN- $\gamma$ antibodies, in all cell lines tested (not shown).

A comparative analysis of several cell lines of neural origin revealed that a generally low level of MV-specific transcriptional efficiency (as determined by the steady-state levels of the $\mathrm{N}$-specific mRNAs per infected cell) and the occurrence of highly polar expression gradients for the MV-specific mRNAs roughly correlated with the ability of the corresponding cell line to express high levels of MxA protein in response to MV infection (Table 1). This was most pronounced for the glioma cell lines D-32 and D-54 and was slightly less pronounced for U-251 and H-4 (32). The neuronal cell lines did not express MxA after MV infection, but MxA expression could be induced by exogenous IFN- $\beta$ (Table 1 ).

These results indicate that a rapid and high level of expression of endogenous MxA may occur in brain cells upon MV infection, which roughly correlates with the extent of transcriptional restrictions observed in the persistently infected human brain.

Downregulation of MV synthesis in stably MxA-transfected brain cells. To correlate restriction of MV gene expression in brain cells with the expression of $\mathrm{MxA}, \mathrm{U}-87$ cells were chosen for stable transfection of MxA because they did not express detectable amounts of endogenous MxA after MV infection but could be induced to do so by exogenous IFN treatment (Table 1). Compared with U-138, A-172, and the neuronal cell lines, which were also negative for $\mathrm{MxA}$ upon $\mathrm{MV}$ infection, U-87 cells are highly permissive for MV replication, as indicated by the steady-state levels of the $\mathrm{N}$-specific transcripts (Table 1). Thus, potential MxA-dependent restrictions of primary viral gene functions should be easily identified.

After transfection, several independent G-418-resistant U-87 clones were tested for their ability to express the MxA protein by indirect immunofluorescence staining and subsequent analysis by FACscan. In addition, Western blot analyses were performed to confirm the expression of the entire protein (not shown). Although almost $100 \%$ of the transfected cells stained positive for MxA, individual differences between clones that were high expressors (represented by $\mathrm{U}-87-\mathrm{H} 4$ and $\mathrm{U}-87-$ D11) and those that were intermediate expressors (U-87-E4 
a.

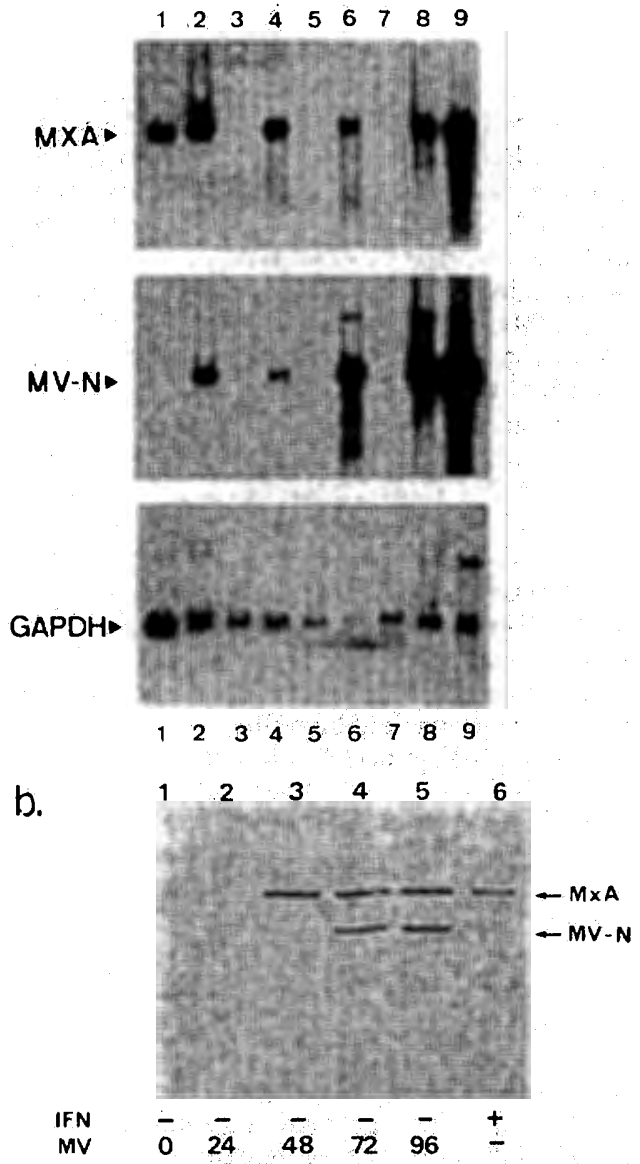

C.

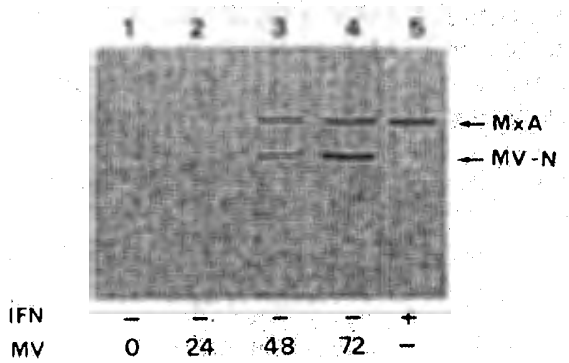

FIG. 1. Expression of MxA proteins in MV-infected human neural cells. (a) Each $10 \mu \mathrm{g}$ of total RNA isolated from IFN- $\beta$-treated U-251 glioma cells $(1,000 \mathrm{U} / \mathrm{ml}$ for $24 \mathrm{~h}$ ) (lane 1$)$ and different brain regions of three patients with SSPE (patient A, lanes 2 to 4 ; patient $B$, lanes 5 and 6; patient $C$, lanes 7 to 9) was separated on formaldehydecontaining agarose gels, blotted, and hybridized to labeled probes specific for MxA (upper panel), MV N mRNA (middle panel) and rat glyceraldehyde-3-phosphate dehydrogenase (GAPDH) (bottom panel). The positions of the corresponding mRNA transcripts are indicated by arrowheads, and the bands migrating more highly, visible in the MV N-specific hybridization, represent bicistronic virus-specific transcripts. (b and c) Western blot analyses of each 10- $\mu \mathrm{g}$ total protein extract of D-54 (b) and HEL (c) cells infected with MV (MOI of 0.1) for the time intervals indicated (b, lanes 1 to 5 ; c, lanes 1 to 4 ) or left uninfected but treated with exogenous IFN- $\beta(1,000 \mathrm{U} / \mathrm{ml}$ for $24 \mathrm{~h})(\mathrm{b}$, lane 6; c, lane 5). Blots were stained with monoclonal antibodies
TABLE 1. Expression of MxA proteins in human brain cells ${ }^{a}$

\begin{tabular}{lccc}
\hline \multirow{2}{*}{ Cell type } & $\begin{array}{c}\text { Altenuation of MV } \\
\text { transcription }^{a}\end{array}$ & \multicolumn{2}{c}{ MxA expression } \\
\cline { 3 - 4 } & MV & IFN- $\beta$ \\
\hline SSPE brain & / +++ & $+^{c}$ & $+^{d}$ \\
D-32 & L +++ & + & + \\
D-54 & $\mathrm{L}+++$ & + & + \\
U-251 & $\mathrm{I} /++$ & + & + \\
U-138 & $\mathrm{I} /+$ & - & - \\
H-4 & $\mathrm{I} /++$ & + & + \\
U-87 & $\mathrm{H} /++$ & - & + \\
A-172 & $\mathrm{I} /++$ & - & - \\
SK-N-MC & $\mathrm{L} /+$ & - & + \\
SK-N-BE & $\mathrm{I} /++$ & - & + \\
IMR-32 & $\mathrm{I} /++$ & \\
\hline
\end{tabular}

a Transcriptional efficiency of MV was determined as copy numbers of the $\mathrm{N}$-specific transcript per cell. MV transcription gradients reflecting the relative frequencies of the MV-specific distal mRNAs in relation to their individual N gene mRNAs $(n=100 \%)$ were determined by quantitative Northern blot analyses of RNA isolated after $40 \mathrm{~h}$ of MV infection (MOI of 0.5 ) as described previously (30). Data shown for the SSPE brains and the cell lines D-32, D-54, U-251, and U-138 have been published previously (32). Cell lines D-32, D-54, $\mathrm{U}-251, \mathrm{U}-138, \mathrm{U}-87$, and A-172 are glioblastomas; $\mathrm{H}-4$ is a neuroglioma; and SK-N-MC, SK-N-BE, and IMR-32 are cell lines of neuronal origin. Transcriptional efficiency is indicated as high ( $\mathrm{H}$ [similar to nonneural controls, ranging between 15,000 and 20,000 copies per cell]), low (L [ranging from 2,000 to 6,000 copies per cell)) and intermediate (I). The extent of attenuation of the MV-specific distal mRNAs was graded according to the following scale: +++ , strongly polar gradient, to + , flat, Vero cell-like gradient.

${ }^{b}$ Expression of the IFN-inducible MxA protein was determined in each $10-\mu \mathrm{g}$ total protein extract of each individual cell line after infection with MV (MOI of 1) for 24,48 , and $72 \mathrm{~h}$ or, alternatively, after $24 \mathrm{~h}$ of IFN- $\beta$ - treatment $(1,000$ $\mathrm{U} / \mathrm{ml}$ ) by Western blot analysis. MxA expression in brain tissue was tested in three independent cases of SSPE by indirect immunofluorescence staining of frozen tissue sections.

c See Fig. 1a.

$d$ Suggested by the presence of IFN in cerebrospinal fluid $(13,14)$.

and U-87-A8) of MxA protein could be observed. As negative controls, the parental line (U-87) and two clones stably transfected with the vector DNA (U-87-K4, U-87-K13) were used (Table 2 and Fig. 2). The antiviral activity of the transfected MxA protein in the high-level MxA-expressing clones (U87-H4 and U-87-D11) was confirmed by its ability to interfere with VSV replication in a plaque reduction assay as described previously (24) (data not shown).

After $18 \mathrm{~h}$ of infection with MV (MOI of 1), the appearance of the cytopathic effect in the individual cultures correlated inversely with the expression of MxA (Fig: 2). Widespread cytopathic effect characterized by the formation of giant cells was apparent in the non-MxA-expressing control cells (representatively shown for U-87-K4 in Fig. 2a), while a progressively less-pronounced cytopathic effect was observed in U-87-A8 and U-87-H4 cells (Fig. 2b and c). No cytopathic effect was apparent in U-87-D11 cells, which were undistinguishable from uninfected U-87 cells (Fig. 2d). Thus, resistance of U-87 cells to MV infection is conferred by transfection of MxA, similar to our previous observations with stably MxA-transfected human monocytes (U-937-MxA) (35). Comparable to the titers found for U-937-MxA cells, the titers of infectious virus released from U-87-MxA cells after the first replication cycle were reduced up to 100 -fold, depending on the level

against the $60-\mathrm{kDa} \mathrm{MV} \mathrm{N}$ protein and the $78-\mathrm{kDa} \mathrm{MxA}$ protein (the positions of the corresponding signals are indicated by arrows). 
TABLE 2. MV yield in stably MxA-transfected human brain cells and nonexpressing controls

\begin{tabular}{cccccccc}
\hline \multirow{2}{*}{ MOI } & \multicolumn{7}{c}{ MV titer (MxA expression,,-++++$)^{b}$ in cell line } \\
\cline { 2 - 7 } & $\mathrm{U}-87(-)$ & $\mathrm{K} 4(-)$ & K13 $(-)$ & A8 $(+)$ & E4 $(+)$ & H4 $(+++)$ & D11(+++) \\
\hline 10 & $7 \times 10^{3}$ & $5 \times 10^{3}$ & $4 \times 10^{3}$ & $2 \times 10^{2}$ & $4 \times 10^{2}$ & $2 \times 10^{2}$ & $7 \times 10^{1}$ \\
1 & $6 \times 10^{2}$ & $1 \times 10^{3}$ & $5 \times 10^{2}$ & $1 \times 10^{2}$ & $4 \times 10^{1}$ & $1 \times 10^{1}$ & $<10^{1}$ \\
0.1 & $3 \times 10^{2}$ & $2 \times 10^{2}$ & $1 \times 10^{2}$ & $1 \times 10^{1}$ & $<10^{1}$ & $<<10^{1}$ & \\
\hline
\end{tabular}

a Supernatants were removed after $24 \mathrm{~h}$ of infection with the input MOIs indicated and titrated on Vero cells. The titers indicated were determined in triple assays. $b-$ to +++ indicates the level of MxA expression in the individual cell clone as determined by indirect immunofluorescence and FACscan.

of MxA expression in the culture (Table 2). The yield of infectious virus was reduced in U-87-H4 and U-87-D11 cells between 50 - and 100 -fold compared with that in the controls, whereas the effect was less pronounced in U-87-E4 and U-87-A8 cells. In addition, attenuation of MV replication was less pronounced in all cell lines at high MOIs, indicating that the resistance conferred by $\mathrm{MxA}$ can be overcome by high doses of virus. In contrast to our results with U-937-MxA cells, however, accumulation of the MV $N$ and $P$ proteins was reduced within the first replication cycle in MxA-expressing U-87-cells (U-87-H4 and U-87-D11) compared with that in the MxA-nonexpressing controls (represented by U-87-K4) (Fig. 3). After infection with an MOI of 10 (Fig. 3a, lanes 1, 3, and 5), the steady-state levels of the MV N and (particularly visible in the figure) the MV $P$ proteins were reduced, whereas MV $\mathrm{N}$-specific signals were almost absent from U-87-MxA cells after infection with an MOI of 1 (Fig. 3a, lanes 4 and 6). Interestingly, the extent of restriction of MV proteins was directly correlated with the different amounts of $\mathrm{MxA}$ expressed in U-87-H4 and U-87-D11 cells as determined by FACscan (Fig. 3b).
Restriction of MV-specific transcription in U-87-MxA cells. MV-specific RNA synthesis in U-87-H4, U-87-D11, and, for control, U-87-K4 cells was analyzed $16 \mathrm{~h}$ after infection with an MOI of 1 by in vivo labeling with ${ }^{32} \mathrm{P}_{i}$ for $6 \mathrm{~h}$ in the presence of actinomycin D (Fig. 4a). Synthesis of cellular RNAs was abolished (see Materials and Methods), and signals specific for the major MV-specific subgenomic mRNAs, except $\mathrm{L}$, were detected in all three cell lines. However, in U-87- 44 and U-87-D11 cells, MV N- and P-specific transcripts were present to only 10 and $13 \%$, respectively (Fig. 4a, lanes 2 and 3 ) compared with those in U-87-K4 cells (Fig. 4a, lane 1). To investigate the MxA-dependent regulation of MV primary transcription, cells (U-87 K4, U-87-E4, U-87-H4, and U-87D11) were directly labeled during the first $6 \mathrm{~h}$ after MV infection with an MOI of 10 in the presence of actinomycin D and cycloheximide (Fig. 4b). Under these conditions, the relative expression levels for the only detectable primary MV-specific N (and P) transcripts were $72 \%$ for U-87-E4 (Fig. $4 b$, lane 3 ), $47 \%$ for U-87-H4 (Fig. 4 b, lane 2 ), and $32 \%$ for U-87-D11 (Fig. 4b, lane 4) compared with those for the non-MxA-expressing U-87-K4 cells (Fig. 4b, lane 1). Synthesis
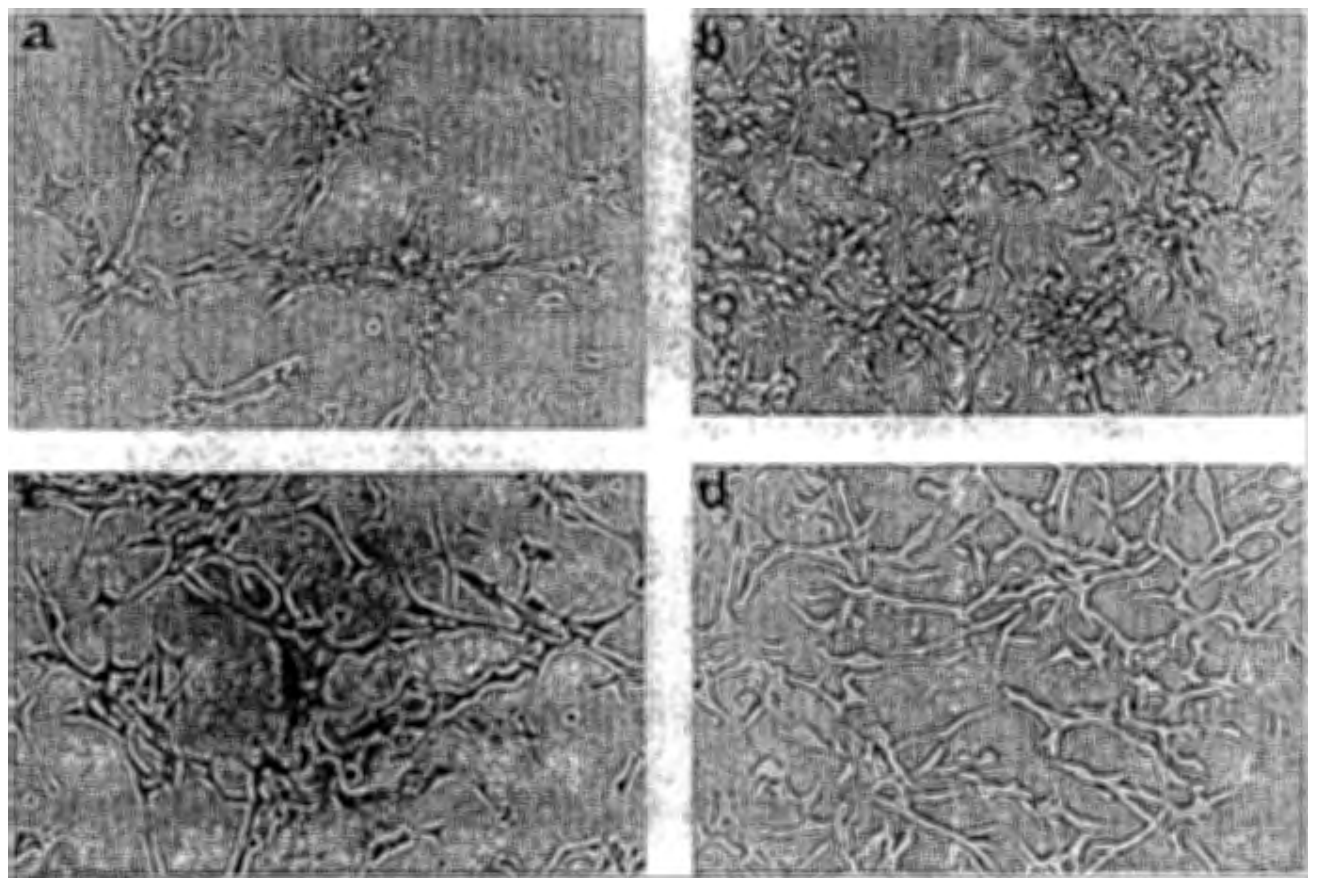

FIG. 2. Morphology of MV-infected U-87-MxA cells. Transfected cell lines (MxA expression graded by - to ++++ ) were infected with MV (MOI of 1 ) for $18 \mathrm{~h}$. The MV-specific cytopathic effect is evident by rounding of the cells and formation of large syncytia (a). (a) Clone U-87-K4 $(-)$. (b) Clone U-87-A8 (+). (c) Clone U-87-H4 $(+++)$. (d) Clone U-87-D11 $(++++)$. In panel a, significant amounts of cells were already detached. 
a.

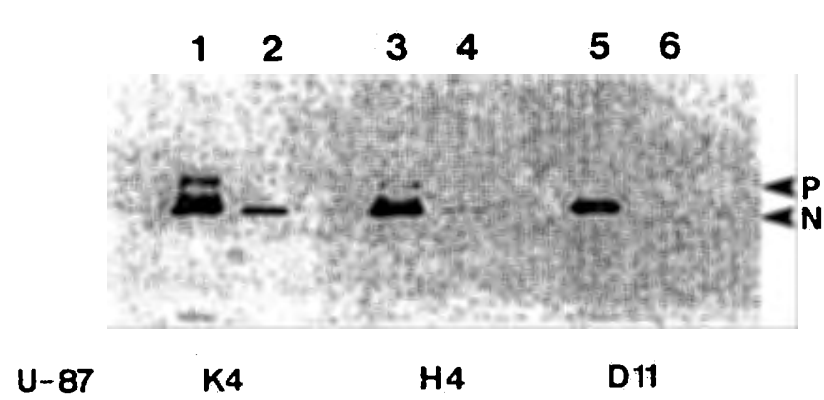

b.

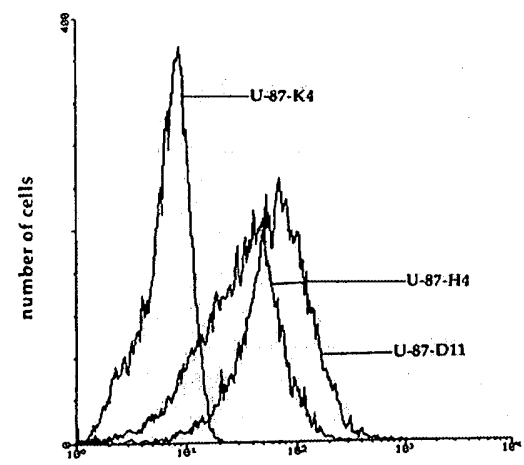

$\log$ fluorescence intensity

FIG. 3. MV N-specific protein expression in U-87-MxA cells. (a) Each 10- $\mu$ g total protein extract from U-87-K4 (lanes 1 and 2), U-87-H4 (lanes 3 and 4), and U-87-D11 (lanes 5 and 6) cells infected with MV at an MOI of 10 (lanes 1,3 , and 5) or 1 (lanes 2,4 , and 6 ) for $18 \mathrm{~h}$ was analyzed by Western blotting with a polyclonal anti-MV serum (the positions of the $\mathbf{N}$ and $\mathrm{P}$ proteins are indicated by arrows). (b) The expression of the MxA protein in U-87-K4-, U-87- $\mathrm{H} 4$, and U-87-D11 cells used for the infection experiment in Fig. 3a was determined by indirect immunofluorescence with a monoclonal antiMxA antibody as described previously (35).

of MV-specific primary transcripts could not be detected with lower input MOIs (not shown).

Because RNase activities associated with subviral particles of VSV isolated from IFN-treated cells have been described (18), additional restrictions provided by an altered stability of MV-specific transcripts in U-87-K4, U-87-A8, and U-87-D11 cells were analyzed. After $16 \mathrm{~h}$ of infection, cells were pulselabeled for $2 \mathrm{~h}$ and subsequently chased for 3 and $6 \mathrm{~h}$ (Fig. 4c). As for the previous long-term labeling experiments (Fig. 4a), the general transcriptional efficiency correlated inversely with the level of MxA expression in the cell lines (Fig. 4c, lanes 1, 4, and 7). In this particular experiment, overall virus-specific transcription, as determined by the frequencies of the $\mathrm{N}$ - and P-specific transcripts, was reduced by $30 \%$ for U-87-A8 and by $65 \%$ for U-87-D11 compared with that for the control. However, no significant differences for the stability of the MVspecific transcripts (referring to the monocistronic as well as the polycistronic RNAs) in the cell lines analyzed could be a.

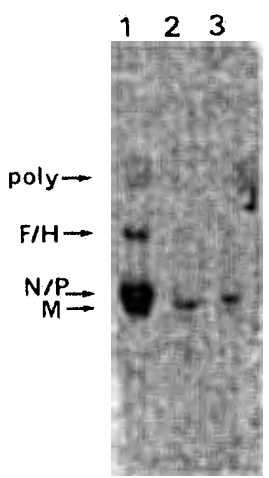

b.

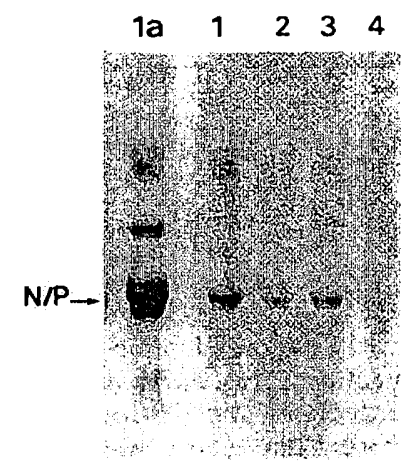

C.

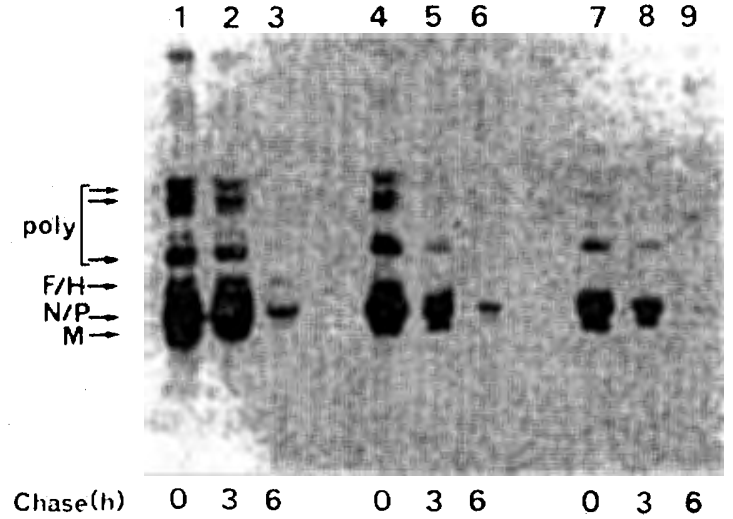

FIG. 4. MV-specific transcription in U-87-MxA cells. (a) MVspecific RNA synthesis was determined by a 6-h labeling in the presence of ${ }^{32} \mathrm{P}_{\mathrm{i}}$ and $20 \mu \mathrm{g}$ of actinomycin $\mathrm{D}$ per $\mathrm{ml}$ after $18 \mathrm{~h}$ of infection with an MOI of 1 in U-87 transfectants expressing no (lane 1) or high levels (lanes 2 and 3 ) of MxA proteins. The positions of the mono- and polycistronic MV-specific transcripts are indicated by arrows. (b) Primary synthesis of MV-specific transcripts in U-87-K4 (lane 1), U-87-H4 (lane 2), U-87-E4 (lane 3), and U-87-D11 (lane 4) cells was determined by direct labeling within the first $6 \mathrm{~h}$ after infection in the presence of ${ }^{32} \mathrm{P}_{\mathrm{i}}(500 \mu \mathrm{Ci} / \mathrm{ml})$, cycloheximide $(20$ $\mu \mathrm{g} / \mathrm{ml})$, and actinomycin $\mathrm{D}(20 \mu \mathrm{g} / \mathrm{ml})$. The positions of the $\mathrm{N}$ - and P-specific transcripts are indicated. (For comparison, the positive control of the long-term labeling experiment [Fig. 4a, lane 1] that was performed in parallel has been mounted [Fig. 4b, lane 1a].) Signals were quantified by phosphorimaging. Because they were extremely weak, the laser printer image is shown instead of an X-ray exposure. (c) U-87-transfectants expressing no (U-87-K4, lanes 1 to 3), intermediate (U-87-A8, lanes 4 to 6), or high (U-87-D11, lanes 7 to 9 ) levels of MxA proteins were pulse-labeled with ${ }^{32} \mathrm{P}_{\mathrm{i}}$ after $18 \mathrm{~h}$ of infection (MOI of 1) for $2 \mathrm{~h}$ in the presence of $20 \mu \mathrm{g}$ of actinomycin D per $\mathrm{ml}$ and subsequently chased for the time intervals indicated. RNAs were isolated and separated by gel electrophoresis. The positions of the mono- and polycistronic transcripts are indicated by arrows. Signals were quantified by phosphorimaging.

identified-(Table 3). (It should be noted that signals not visible in the figure [e.g., F/H in Fig. 4c, lanes 5 to 9] were detectable and quantifiable by phosphorimaging.) Interestingly, in the exposure shown in Fig. 4c, signals specific for the distal mRNAs $(\mathrm{F} / \mathrm{H})$ can be seen in U-87-K4 cells $6 \mathrm{~h}$ after the chase (Fig. 4c, lane 3) but not in U-87-D11 cells after a 3-h chase (Fig. 4c, lane 8), although the $\mathrm{N}$ - and $\mathrm{P}$-specific signals were 
TABLE 3. Stability of MV-specific monocistronic mRNAs in U-87-MxA cells

\begin{tabular}{lccc}
\hline \multirow{2}{*}{ MV mRNA } & \multicolumn{3}{c}{ Half-life $(h)$ of MV-specific mRNA in cell line } \\
\cline { 2 - 4 } & U-87-K4 & U-87-H4 & U-87-D11 \\
\hline N/P & 3 & 2.5 & 3 \\
M & 3.5 & 3 & 3 \\
F/H & 3.6 & 3 & 3.2 \\
\hline
\end{tabular}

${ }^{a} \mathrm{~N}$ - and $\mathrm{P}$-specific and $\mathrm{F}$ - and $\mathrm{H}$-specific signals were comigrating and could not be quantified individually.

${ }^{b}$ The half-lives of the MV-specific transcripts in U-87-MxA cells were determined after a pulse-labeling for $2 \mathrm{~h}$ and subsequent chasing for 3 and $6 \mathrm{~h}$ as shown in Fig. 4c. Signals for the discernible MV-specific RNAs were quantified by phosphorimaging. Note that bands not visible in Fig. $4 c$ could be detected by this procedure.

c U-87 cells expressed either no (U-87-K4 [see Fig. 4c, lanes 1 to 3]) or high (U-87-H4 and U-87-D11 [see Fig. 4c, lanes 4 to 6 and 7 to 9, respectively]) levels of $\mathrm{MxA}$.

comparatively higher for the U-87-D11 cells (again, compare lanes 3 and 8 in Fig. 4c), thus indicating an underrepresentation of the distal mRNAs in this cell line.

Decreased frequency of the distal mRNAs in MxA-expressing cells. Signals for the distal MV-specific mRNAs in U-87MxA cells were generally weak under in vivo labeling conditions because of the attenuation of the overall MV-specific transcription (Fig. 4). Therefore, the steady-state levels of the $\mathrm{N}$ - and $\mathrm{H}$-specific mRNAs in the U-87-H4 and U-87-K13 cell lines $24 \mathrm{~h}$ after infection with input MOIs of 10 and 1, respectively, were comparatively analyzed (Fig. 5). The RNAs isolated from U-87-H4 cells were applied in 10-fold excess over U-87-K13 RNAs to roughly adjust the concentrations of the $\mathrm{N}$-specific transcripts (Fig. 5a). In fact, in this particular experiment, the signal intensities for the $\mathrm{N}$-specific transcript in U-87-H4 cells (Fig. 5a, lane 3) were 1.5-fold higher than those for U-87-K13 cells (Fig. 5a, lane 1) after infection with an MOI of 10 and 1.2-fold higher after infection with an MOI of 1 (Fig. 5a, lanes 2 and 4, respectively) in U-87-H4 cells. Hybridization of the same RNAs with the $\mathrm{H}$-specific probe

a.

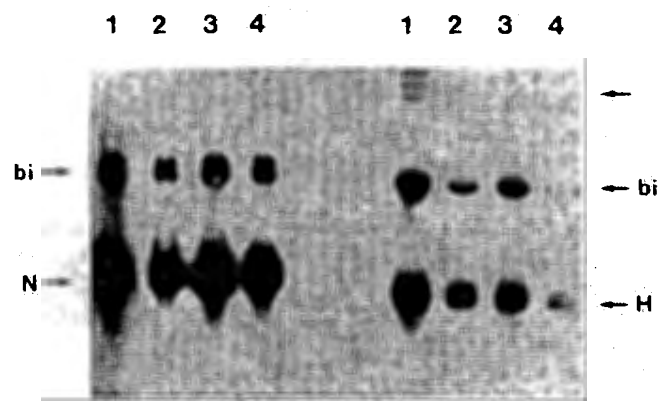

FIG. 5. Relative frequencies of the MV-specific distal mRNAs in U-87-MxA cells. Each $2 \mu \mathrm{g}$ of RNA isolated from U-87-K13 cells (a and $b$, lanes 1 and 2 ) and $20 \mu \mathrm{g}$ of RNA from U-87-H4 cells (a and $b$, lanes 3 and 4) after infection with MOIs of 10 ( $a$ and $b$, lanes 1 and 3 ) and 1 (a and $b$, lanes 2 and 4 ) were separated on formaldehydecontaining agarose gels, blotted, and hybridized to riboprobes specific for the MV N-specific (a) and MV H-specific (b) positive-strand RNAs. Specific signals (indicated by arrows for the mono- and bicistronic [bi] transcripts) were quantified by phosphorimaging. The high-molecular-weight bands in panel $b$ could not be reliably identified. revealed that, in $\mathrm{U}-87-\mathrm{K} 13$ cells, the $\mathrm{H}$-specific mRNA was expressed at relative frequencies of 22 and $15 \%$, respectively (Fig. 5b, lanes 1 and 2), whereas in $\mathrm{H} 4$ cells the relative frequencies were only 5 and $0.2 \%$ of those of the corresponding N-specific mRNAs (Fig. 5b, lanes 3 and 4). Again, restrictions are less pronounced upon high doses of infection (compare Table 2 and Fig. 3 and 4).

Together with the data obtained by in vivo labeling, these results indicate that the general efficiency of MV-specific transcription and the relative frequencies of the distal MVspecific mRNAs are attenuated in MxA-expressing $\mathrm{U}-87$ cells.

\section{DISCUSSION}

Our data show that the cytoplasmic human IFN-inducible MxA protein is able to confer resistance to $\mathrm{MV}$ infection in brain cells. In these cells, MxA-dependent restrictions of MV gene expression are similar to those observed previously for VSV in affecting the synthesis of virus-specific RNAs (37). The attenuation, which is not primarily linked to destabilization of the MV transcripts, was observed for both total transcriptional efficiency and for the relative frequencies of the distal mRNAs. Because this particular transcriptional pattern is typically observed in human brain cells after primary MV infection (30, 32) and in persistently infected human brain tissue (33), MxA may be considered an important intracellular factor for the establishment of MV persistence in the human central nervous system.

Although MV nucleocapsids are ubiquitously present in SSPE brain tissue, glial cells and neurons are the main target cells for MV (34). In tissue culture, detectable amounts of MxA are expressed in neuroblastoma cells after stimulation with exogenous IFN, but not after MV infection itself (Table 1). Recent mRNA analyses confirmed that MV infection of these cells does not induce the synthesis of IFN- $\beta$-specific mRNA (28). In contrast, glial cells respond to MV infection with a rapid induction of IFN- $\beta$, as revealed by Northern blots, analyses of cell supernatants, and the inhibition of $\mathrm{MxA}$ induction by anti-IFN- $\beta$ antibodies (reference 29 and this report). Thus, the expression of $\mathrm{MxA}$ in neurons in vivo is probably induced by exogenous IFN released from MV-infected glial cells.

In U-87-MxA cells, the extent of resistance to MV infection strictly correlates with the expression level of the transfected $\mathrm{MxA}$ in the individual U-87-MxA clones, thus rendering an artificial inhibitory effect due to the integration site of the transfected DNA unlikely. The MxA-mediated inhibition of MV transcription, and subsequently virus release, was less pronounced than that of VSV (24). However, we could enhance this effect with exogenous IFN- $\beta$ (data not shown), indicating that MxA may be necessary, but not sufficient, to completely inhibit MV replication in IFN-treated cells. The role of other IFN-inducible proteins in regulating MV gene functions has not yet been analyzed. It is conceivable that the incomplete MxA-dependent inhibition of $\mathrm{MV}$ in brain cells may be further enhanced by additional differentiation-dependent control mechanisms affecting viral transcription and/or translation $(33,42)$.

In contrast to our findings in U-937 monocytes, expression of MxA affected the expression of internal MV structural proteins $\mathbf{N}$ and $\mathbf{P}$ rather than that of the glycoproteins (Fig. 3a [35]). The expression of $\mathrm{N}$ protein, clearly coinciding with the expression of MxA in the individual cell lines, is undoubtedly strongly affected at an input MOI of 1 (Fig. 3a, lanes 2, 4, and 6 ). At higher doses of virus (Fig. 3a, lanes 1, 3, and 5), the reduction of $\mathrm{N}$ protein expression seems to be less pro- 
nounced, whereas it is clearly visible for the second abundant protein, the $P$ protein. This finding may in part be explained by the subsequent RNA analyses (Fig. 4b [also described below]). On the other hand, the steady-state levels of $\mathrm{N}$ protein detected $18 \mathrm{~h}$ postinfection, particularly with high levels of input MOIs, may also reflect the presence of residual $\mathrm{N}$ protein derived from the infecting particles. Indeed, we could show that in some brain cell lines, including $\mathrm{U}-87$, the half-lives of $\mathrm{N}$ proteins range from $12 \mathrm{~h}$ to $16 \mathrm{~h}(29 \mathrm{a})$.

In U-87-MxA cells, the overall efficiency of MV-specific transcription proved to be highly reduced (Fig. 4a). The effect on viral primary RNA synthesis, analyzed in the presence of cycloheximide, was apparently less pronounced (around $60 \%$ instead of $90 \%$ [Fig. 4a and b]). Signals obtained for MV primary RNA synthesis are, however, in general substantially weak because the primary transcription of $\mathrm{MV}$ is rather slow compared with that of VSV. Thus, MV primary RNA synthesis can only be detected with high doses of virus (high MOI of 10). Under these infection conditions, however, the MxA-dependent downregulation of MV replication was less effective (Fig. 3 and Table 2). In that context, however, it should be noted that, for VSV as well, the inhibition of primary RNA synthesis as determined in the presence of cycloheximide is less pronounced than that determined in the absence of the drug (37).

Transcriptional regulation of $\mathrm{MV}$ in $\mathrm{U}-87-\mathrm{MxA}$ cells also affects the relative frequencies of the distal mRNAs, leading to highly polar expression gradients as observed for VSV in mouse 3T3-MxA and human U-937-MxA cells (Fig. 4c and 5) $(35,37)$. Although, as is the case for VSV, the distal mRNAs are longer than the proximal mRNAs located at the $3^{\prime}$ end of the genome, a selective instability could not be observed for these transcripts in U-87-MxA cells because the half-lives of the individual transcripts were comparable (Fig. 5 and Table 3). Although we cannot formally rule out an enhanced RNase activity, it is not likely that this activity would be confined to the 2-h labeling period used in the pulse-chase experiment and it would not affect the half-lives of the individual mRNAs during the chase period. In addition, no evidence for an enhanced instability of the distal mRNAs could be detected after MV infection of D-54 cells that spontaneously reveal strongly polar expression gradients for the MV-specific mRNAs in the presence of high amounts of endogenous MxA (not shown).

Previous studies clearly indicated that the antiviral activities of Mx proteins are dependent on their intracellular localization and are specific for different viruses $(23,44)$. Our study provides direct evidence that resistance conferred by $\mathrm{MxA}$ for the same virus (MV) is host cell dependent in attenuating viral transcription in brain cells and synthesis of MV glycoproteins in monocytes without any impairment of viral transcription (35). In support of the cell type specificity of MxA to restrict MV gene expression, growth of MV was unaffected in MxAtransfected Vero cells $(15,29 a)$.

The hypothesis that MxA-mediated mechanisms imposed on MV gene expression have to be rather different is also supported by their ability to distinguish between VSV and MV in U-937 cells and not in brain cells (35). Unfortunately, the comparative analysis could not be extended to the originally established 3T3-MxA cells (24), because these cells and the parental 3T3 cell line are not permissive for MV replication.

The basis for the host cell-specific differences observed for MxA-dependent MV gene regulation in U-937 and U-87 cells is not understood, although they seem to be mutually exclusive. All of our attempts to find alterations of MV transcription in monocytes failed (35). In contrast to the parental U-87 cells, MV transcription was already substantially low and the expression gradient for the MV-specific transcripts was highly polar in the parental U-937 cell line, indicating that, in these cells, transcriptional attenuation of $\mathrm{MV}$ occurs independently of MxA expression. The primary site of interference with MV replication for MxA in U-87 brain cells is viral RNA synthesis, and, consequently, the steady-state levels of the viral distal mRNAs, including those specific for the glycoproteins, are extremely low. However, additional control mechanisms imposed on posttranscriptional levels cannot be ruled out.

The mode of action of $\mathrm{Mx}$ proteins has not been elucidated yet. They have been designated as members of a new class of GTPases with antiviral activity (38). Tripartite GTP binding consensus elements have been identified at the $\mathrm{N}$ termini of the proteins (11), and more recently, their capacity to bind and to hydrolyze GTP has been confirmed (25). Moreover, by use of deletion mutants, evidence for a relationship between their antiviral activity and a functional GTP binding motif has been obtained $(25,43)$. However, because deletions or mutations within carboxy-terminal sequences of MxA proteins have been associated with their complete functional loss, sites critical for the antiviral effect, probably directly interacting with viral constituents, have been suggested (43). The functional relevance of this domain was further supported by a mutant with just one amino acid exchange at position 645 that completely lost its ability to interfer with VSV replication but still was able to inhibit influenza virus replication (43).

Physical interactions of MxA with cellular cytoskeletal proteins, such as actin and tubulin, were observed $(10,27)$. Although in vitro MV and VSV transcription and replication have been found to be positively regulated by cellular components, including actin and tubulin $(20,21)$, the ubiquitous expression of these proteins renders a role in cell-type-specific regulation of MV transcription rather unlikely. Unfortunately, all attempts, including our own, to positively identify a direct interaction of $\mathrm{MxA}$ with viral structural proteins have failed (39). Thus, a functional interaction of MxA with viral or host cell constituents, probably related to the ability of MxA to bind and hydrolyze GTP (25), has to be anticipated.

\section{ACKNOWLEDGMENTS}

We thank Jens-Jörg Schnorr and Amiya K. Banerjee for helpful discussions and Lee M. Dunster and Christiane Ingendahl for critical reading of the manuscript.

This work was supported by the Deutsche Forschungsgemeinschaft and by the Schweizerische Nationalfond.

\section{REFERENCES}

1. Aebi, M., J. Fäh, N. Hurt, C. E. Samuel, D. Thomis, L. Bazzigher, J. Pavlovic, O. Haller, and P. Staeheli. 1989. cDNA structures and regulation of two interferon-induced human $\mathrm{Mx}$ proteins. Mol. Cell. Biol. 9:5062-5072.

2. Bigner, D. D., S. H. Bigner, J. Ponten, B. Westermark, M. S. Mahaley, E. Ruoslahti, H. Herschman, L. F. Eng, and C. J. Wikstrand. 1981. Heterogeneity of genotypic and phenotypic characteristics of fifteen permanent cell lines derived from human gliomas. J. Neuropathol. Exp. Neurol. XL:201-229.

3. Billeter, M. A. R. Cattaneo, P. Spielhofer, K. Kaelin, M. Huber, A. Schmid, K. Baczko, and V. ter Meulen. 1994. Generation and properties of measles virus mutations typically associated with subacute sclerosing panencephalitis. Ann. N. Y. Acad. Sci. 724: 367-377.

4. Carrigan, D. R., and K. K. Knox. 1990. Identification of interferon-resistant subpopulations in several strains of measles virus: positive selection by growth of the virus in brain tissue. J. Virol. 64:1606-1615.

5. Cattaneo, R., G. Rebmann, K. Bacako, V. ter Meulen, and M. A. Billeter. 1987. Altered ratios of measles virus transcripts in diseased human brains. Virology 160:523-526.

6. Cattaneo, R., G. Rebmann, A. Schmid, K. Baczko, V. ter Meulen, 
and M. A. Billeter. 1987. Altered transcription of a defective measles virus genome derived from a diseased human brain. EMBO J. 6:681-687.

7. Fort, P., L. Marty, M. Piechaczyk, S. Elsalrouty, C. Dani, P. Janteur, and J. M. Blanchard. 1985. Various rat adult tissues express only one major mRNA species from the glyceraldehyde3-phosphate dehydrogenase. Nucleic Acids Res. 13:1431-1442.

8. Gunning, P., J. Leavitt, G. Muscat, S.-Y. Ng, and L. Kedes. 1987. A human $\beta$-actin expression vector system directs high level accumulation of antisense transcripts. Proc. Natl. Acad. Sci. USA 84:4831-4835.

9. Hall, W. W., D. Genius, and V. ter Meulen. 1976. The effect of cycloheximide on the replication of measles virus. J. Gen. Virol. 35:579-582.

10. Horisberger, M. A. 1992 . Interferon-induced human protein MxA is a GTPase which binds transiently to cellular proteins. J. Virol. 66:4705-4709.

11. Horisberger, M. A., G. K. McMaster, H. Zeller, M. G. Wathelet, J. Dellis, and J. Content. 1990. Cloning and sequence analyses of cDNAs for interferon- and virus-induced human $\mathrm{Mx}$ proteins reveal that they contain putative guanine nucleotide binding sites: functional study of the corresponding gene promoter. J. Virol. 64:1171-1181.

12. Huang, T., J. Pavlovic, P. Staeheli, and M. Krystal. 1992. Overexpression of the influenza virus polymerase can titrate out inhibition by the murine Mx1 protein. J. Virol. 66:4154-4160.

13. Huttenlocher, P. R., D. L. Picchietti, R. P. Roos, N. P. Cashman, B. Horowitz, and M. S. Horowitz. 1986. Intrathecal interferon in subacute sclerosing panencephalitis. Ann. Neurol. 19:303-305.

14. Joncas, J. H., L. R. Robillard, A. Boudreault, M. Leyritz, and B. J. M. McLaughlin. 1976. Interferon in serum and cerebrospinal fluid in subacute sclerosing panencephalitis. Can. Med. Assoc. J. 115:309.

15. Kopp, U., U. Meier-Dieter, E. Koch, and O. Haller. 1993. Human MxA protein in transfected Vero cells: no inhibition of paramyxoviruses, abstr. P17-43, p. 174. Abstr. IXth Int. Congr. Virol., Glasgow, Scotland, 1993.

16. Kraus, E., S. Schneider-Schaulies, M. Miyasaka, T. Tamatani, and J. Sedgwick. 1991. Augmentation of major histocompatibility complex class I and ICAM-1 expression on glial cells following measles virus infection: evidence for the role of type-1 interferon. Eur. J. Immunol. 22:175-182.

17. Krug, R. M., M. Shaw, B. Broni, G. Shapiro, and O. Haller. 1985. Inhibition of influenza viral mRNA synthesis in cells expressing the interferon-induced $M x$ gene product. J. Virol. 56:201-206.

18. Kumar, R., D. Chattopadhyay, A. K. Banerjee, and G. C. Sen 1988. Ribonuclease activity is associated with subviral particles isolated from interferon-treated vesicular stomatitis virus-infected cells. J. Virol. 62:641-643.

19. Miyazu, M., T. Morishima, N. Hanada, S. Isomura, and S. Suzuki. 1985. Types of interferon detected in cerebrospinal fluid from patients with viral infections of the central nervous system. J. Infect. Dis. 152:1098-1099.

20. Moyer, S. A., S. C. Baker, and S. M. Horikami. 1990. Host cell proteins required for measles virus reproduction. J. Gen. Virol. 71:775-783.

21. Moyer, S. A., S. C. Baker, J. L. Lessard. 1986. Tubulin: a factor necessary for the synthesis of both Sendai virus and vesicular stomatitis virus RNA. Proc. Natl. Acad. Sci. USA 83:5405-5409.

22. Ogura, H., K. Baczko, B. K. Rima, and V. ter Meulen. 1987. Selective inhibition of translation of the mRNA coding for measles virus membrane protein at elevated temperatures. J. Virol. 61: 472-479.

23. Pavlovic, J., O. Haller, and P. Staeheli. 1992. Human and mouse Mx proteins inhibit different steps of the influenza virus multiplication cycle. J. Virol. 66:2564-2569.

24. Pavlovic, J., T. Zürcher, O. Haller, and P. Staeheli. 1990. Resis- tance to influenza virus and vesicular stomatitis virus conferred by expression of human MxA protein. J. Virol. 64:3370-3375.

25. Pitossi, F., A. Blank, A. Schröder, A. Schwarz, P. Hüssi, M. Schwemmle, J. Pavlovic, and P. Staeheli. 1993. A functional GTP-binding motif is necessary for antiviral activity of Mx proteins. J. Virol. 67:6726-6732.

26. Rager-Zisman, B., J. E. Egan, Y. Kress, and B. R. Bloom. 1984. Isolation of cold-sensitive mutants of measles virus from persistently infected murine neuroblastoma cells. J. Virol. 51:845-855.

27. Ronni, T., K. Melen, A. Malygin, and I. Julkunen. 1993. Control of IFN-inducible MxA gene expression in human cells. J. Immunol. 150:1715-1726.

28. Schneider-Schaulies, J. Unpublished data.

29. Schneider-Schaulies, J., S. Schneider-Schaulies, and V. ter Meulen. 1993. Primary and persistent measles virus infections induce different sets of cytokines in human glial cells. Virology 195:219-228.

29a.Schneider-Schaulies, S. Unpublished data.

30. Schneider-Schaulies, S., U. G. Liebert, K. Baczko, and V. ter Meulen. 1990. Restricted expression of measles virus in primary rat astroglial cells. Virology 177:802-806.

31. Schneider-Schaulies, S., U. G. Liebert, Y. Segev, B. Rager-Zisman, M. Wolfson, and V. ter Meulen. 1992. Antibody-dependent transcriptional regulation of measles virus in persistently infected neural cells. J. Virol. 66:5534-5541.

32. Schneider-Schaulies, S., J. Schneider-Schaulies, M. Bayer, S. Löffler, and V. ter Meulen. 1993. Spontaneous and differentiationdependent regulation of measles virus gene expression in human glial cells. J. Virol. 67:3375-3383

33. Schneider-Schaulies, S., J. Schneider-Schaulies, L. M. Dunster, and V. ter Meulen. Measles virus gene expression in neural cells. Curr. Top. Microbiol. Immunol., in press.

34. Schneider-Schaulies, S., and V. ter Meulen. 1992. Molecular aspects of measles virus induced central nervous system diseases, p. 419-449. In R. P. Roos (ed.), Molecular neurovirology. Humana Press, Inc., Clifton, N.J.

35. Schnorr, J.-J., S. Schneider-Schaulies, A. Simon-Jödicke, J. Pavlovic, M. A. Horisberger, and V. ter Meulen. 1993. MxA-dependent inhibition of measles virus glycoprotein synthesis in a stably transfected human monocytic cell line. J. Virol. 67:4760-4768.

36. Staeheli, P. 1990. Interferon-induced proteins and the antiviral state. Adv. Virus Res. 38:147-200.

37. Staeheli, P., and J. Pavlovic. 1991. Inhibition of vesicular stomatitis mRNA synthesis by human MxA protein. J. Virol. 65:44984501.

38. Staeheli, P., F. Pitossi, and J. Pavlovic. 1993. Mx proteins: GTPases with antiviral activity. Trends Biochem. Sci. 3:268-272.

39. Stranden, A., P. Staeheli, and J. Pavlovic. 1993. Function of the mouse Mx1 protein is inhibited by overexpression of the PB2 protein of influenza virus. Virology 197:642-651.

40. Wikstrand, C. J., F. C. Grahmann, R. D. McComb, and D. D. Bigner. 1985. Antigenic heterogeneity of human anaplastic gliomas and glioma-derived cell lines defined by monoclonal antibodies. J. Neuropathol. Exp. Neurol. 44:229-241.

41. Yoshikawa, Y., K. Mizumoto, and K. Yamanouchi. 1986. Characterization of messenger RNAs of measles virus. J. Gen. Virol. 67:2807-2812.

42. Yoshikawa, Y., and K. Yamanouchi. 1984. Effects of papaverine treatment on replication of measles virus in human neural and nonneural cells. J. Virol. 50:489-496.

43. Zürcher, T., J. Pavlovic, and P. Staeheli. 1992. Mechanisms of human MxA protein action: variants with changes in antiviral properties. EMBO J. 11:1657-1661.

44. Zürcher, T., J. Pavlovic, and P. Staeheli. 1992. Nuclear localization of mouse Mxl protein is necessary for inhibition of influenza virus. J. Virol. 66:5059-5066. 